\title{
NEW COMPACTION METHOD FOR THE PRODUCTION OF LARGE RAMMING PASTE SAMPLES FOR 3D MECHANICAL CHARACTERIZATION
}

\author{
Pierre-Olivier St-Arnaud ${ }^{1}$, Donald Picard ${ }^{1}$, Maxime Noë $1^{1}$, Houshang Alamdari ${ }^{1}$, Donald Ziegler ${ }^{2}$, Mario Fafard ${ }^{1}$ \\ ${ }^{1} \mathrm{NSERC} / \mathrm{Alcoa}$ Industrial Research Chair $\mathrm{MACE}^{3}$ and Aluminium Research Centre - REGAL, 1065 avenue de la Médecine, \\ Université Laval, Québec, QC, G1V 0A6, Canada \\ ${ }^{2}$ Alcoa Canada Primary Metals, Aluminerie de Deschambault, 1 Boulevard des Sources, \\ Deschambault-Grondines, QC, G0A 1S0, Canada
}

Keywords: Aluminium Electrolysis, Apparent Density, Cold Ramming Paste, Compaction Method, Mechanical Properties

\begin{abstract}
To assess the mechanical behavior of ramming paste, representative laboratory samples must be produced for experimental characterization. Experimental data are necessary to feed three-dimensional creep model where radial strain measurements are required. It is thus imperative to perform measurements on a sample large enough to get significant radial strain amplitude. However, the ISO standard fabrication method is restricted to small-size samples. In the present paper, a different compaction process, adapted from the Proctor method, is proposed in order to get larger cylindrical samples of $100 \mathrm{~mm}$ diameter and $200 \mathrm{~mm}$ height. The ramming paste samples are produced in multilayer by dynamic compaction, using a falling weight in a circular pattern over the tamped surface. The baked apparent density obtained by X-Ray computed tomography, or CT scan, and the baked mechanical properties such as compressive strength, have been characterized as a function of the number of layers and the number of impacts.
\end{abstract}

\section{Introduction}

The rammed peripheral seam within the aluminium electrolysis cell is often held responsible for early pots failure induced by molten metal and liquid bath infiltration in the lining. Based on autopsies of failed pots, Sørlie \& Øye [1] pointed out the ramming paste critical role leading to pot failure. Nonetheless, the importance of the ramming paste regarding the performance of the cells is oftentimes overlooked, according to Hiltmann \& Meulemann [2]. The weaknesses of the joints and seams, mainly driven by either insufficient or over-tamping of the paste, are amongst the main factors causing operational problems. Consequently, as ramming paste undergoes various transformations and absorbs the thermal expansion of the cathode blocks during the preheating process, poor state of the rammed parts might lead to the emergence of gaps or cracks in the lining altering the cell's lifespan.

To gain better knowledge on the thermo-mechanical properties of the ramming paste, a representative laboratory sample must be produced. The standard procedure ISO 17544:2004 [3] employing a Fischer Sand Rammer RDC-194 allows one to obtain the rammability of the paste and to produce small size samples, i.e. 50 $\mathrm{mm}$ diameter. However, the three-dimensional mechanical characterization is difficult to perform with small samples, as the measurements of radial strain are often irrelevant. Various methods using hand-held pneumatic rammers or falling weights over a constant distance were performed to compact samples with different diameters. Nonetheless, their dimensions cannot ensure that the radial strain amplitude is enough large to provide significant strain level for the evaluation of the transversal strain (Poisson effect).

Most compaction methods have been reviewed by Orangi et al. [4] in an attempt to develop a sample fabrication method providing comparable compaction level of a representative assembly of the peripheral joint. It was shown that the measured density distribution for a typical section of the seam was ranging between $1.51 \mathrm{~g} / \mathrm{cm}^{3}$ and $1.76 \mathrm{~g} / \mathrm{cm}^{3}$ and the average density obtained for half of the examined assembly was calculated 1.61 $\mathrm{g} / \mathrm{cm}^{3}$. Thereby, the limitations concerning sample density has to be met within the given density range in order to get a representative sample.

Thus, the objective of this paper is to develop a new compaction method to produce larger cylindrical samples in order to feed three-dimensional creep model. To accomplish this goal, the compaction process must take into account the apparent density distribution as a function of the number of layers and impacts. The multilayer approach instead of the one layer compaction was chosen to obtain better evenly compacted samples. Moreover, joints and seams are rammed in multiple layers. The compaction method's calibration curve was determined to set the required parameters to produce samples having a specific green apparent density. A non-destructive testing method, X-Ray computerized tomography (CT), was calibrated with a standard baked sample in order to evaluate the density distribution of the baked specimen, as explained by Picard et al. [5]. Compression tests were conducted at ambient temperature to obtain Young modulus, Poisson's ratio and compressive strength of ramming paste samples baked at $1000^{\circ} \mathrm{C}$ to assess the effects of the compaction parameters on the mechanical properties.

\section{Methodology}

\section{Compaction method}

The developed procedure to obtain samples of $101.6 \mathrm{~mm}$ (4 in) in diameter and $203.2 \mathrm{~mm}$ ( $8 \mathrm{in}$ ) in height was inspired by the ASTM D1557-09 [6] standard test method for laboratory compaction characteristics of soil, commonly referred to as the Modified Proctor Compaction Test. A mechanical rammer with a planar and circular face of $50.8 \mathrm{~mm}$ ( $2 \mathrm{in}$ ) operates to provide a uniform and complete coverage of the specimen surface (Figure 1). The rammer, weighing $2.49 \mathrm{~kg}(5.5 \mathrm{lb})$, falls freely through a distance of $457.2 \mathrm{~mm}$ (18 in) over the tamped surface and repeatedly in a circular pattern to complete two turns. The apparatus is illustrated in Figure 2. 


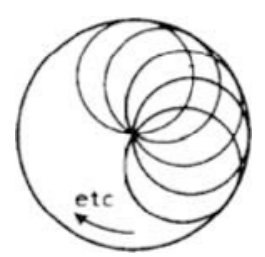

Figure 1. Circular compaction pattern for the mechanical rammer (ASTM D1557-09)

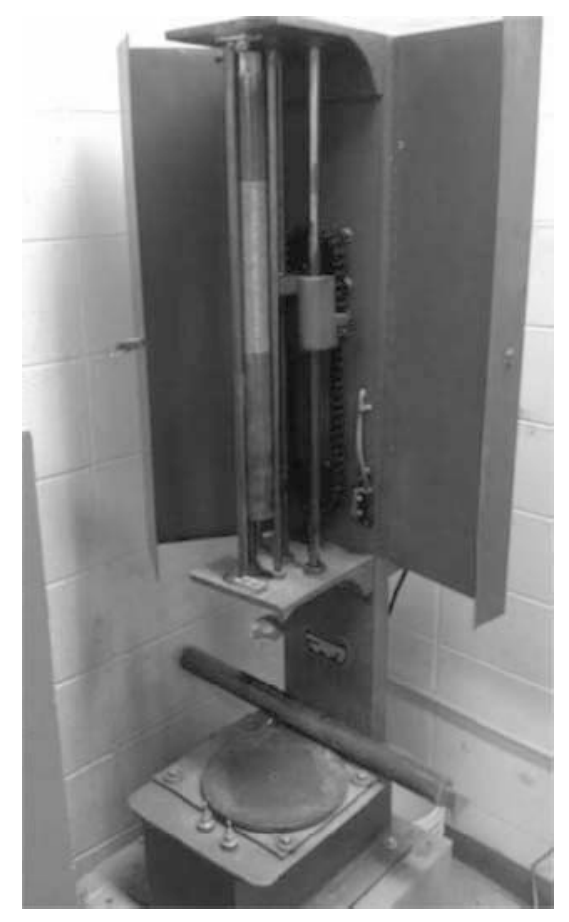

Figure 2. Apparatus used for the compaction of ramming paste: Proctor Mechanical Rammer

In order to achieve samples of greater size than the one mentioned in the ASTM D1557-09 standard, a split cylinder steel mold with the required dimensions for the new procedure was used and the base plate was adapted to fit on the indexation plate of the apparatus. Two methods were tested. For the first method, a total of 10 layers, $275 \mathrm{~g}$ of cold ramming paste per layer, were poured one at the time after each round of compaction. For the second method, 8 layers, $340 \mathrm{~g}$ of paste per layer, were used for compaction. For both cases, the upper surface of the last tamped layer was trimmed to remove the excess material so the compacted specimen was even with the top of the mold. The 10 layer method was accomplished for a total number of impacts ranging from 110 to 220 impacts, thus 11 to 22 impacts per layer. The 8 layer method has been performed for 15 and 16 impacts per layer only. The green apparent densities of the specimens were measured according to ASTM D5502-00 [7]. A precision balance (Sartorius CPA16001S) and a caliper (Mitutoyo CD-12" PSX) were used to measure the weight and dimensions of samples.

\section{Sample baking}

All green ramming paste samples were baked at a temperature of $1000^{\circ} \mathrm{C}$, standing free in a steel box containing 4 samples covered with coke to avoid oxidation. The heating program was set accordingly to ISO 20202:2004 [8]. The baked apparent densities were also measured according to ASTM D5502-00.

\section{$\underline{\text { X-Ray computed tomography }}$}

Eighteen baked samples (Table 1) with different compaction parameters were scanned using a Somatom Sensation 64 at INRSETE Research Centre in Quebec City. As explained by Picard et al. [5] for pre-baked carbon anodes, the density of materials such as carbon can be estimated assuming a linear relation between the CT number expressed in Hounsfield Units (HU) and the density. A calibration must be performed using a representative sample whose density is known.

Table 1. Compaction parameters of the scanned samples

\begin{tabular}{|c|c|c|}
\hline Number of samples & Number of layers & Impacts per layer \\
\hline 3 & 8 & 15 \\
\hline 3 & 8 & 16 \\
\hline 3 & 10 & 12 \\
\hline 3 & 10 & 13 \\
\hline 3 & 10 & 15 \\
\hline 3 & 10 & 17 \\
\hline
\end{tabular}

\section{Compression tests}

The compression tests were carried at ambient temperature with a MTS 311 load frame. In order to remain inside the elastic domain of the baked sample, a load corresponding to approximately $20 \%$ of the compressive strength was applied to evaluate the Young modulus and the Poisson's ratio. The loading rate was set according to the ISO 18515:2007 standard [9], i.e. $0.15 \mathrm{MPa} / \mathrm{s}$. Three axial extensometers and one circumferential extensometer chain-fitted (MTS 632.11F-90) were used for the measurements of the strains (Figure 3). The samples have been sawn and provided with sulfur capping to ensure parallelism between both end surfaces.

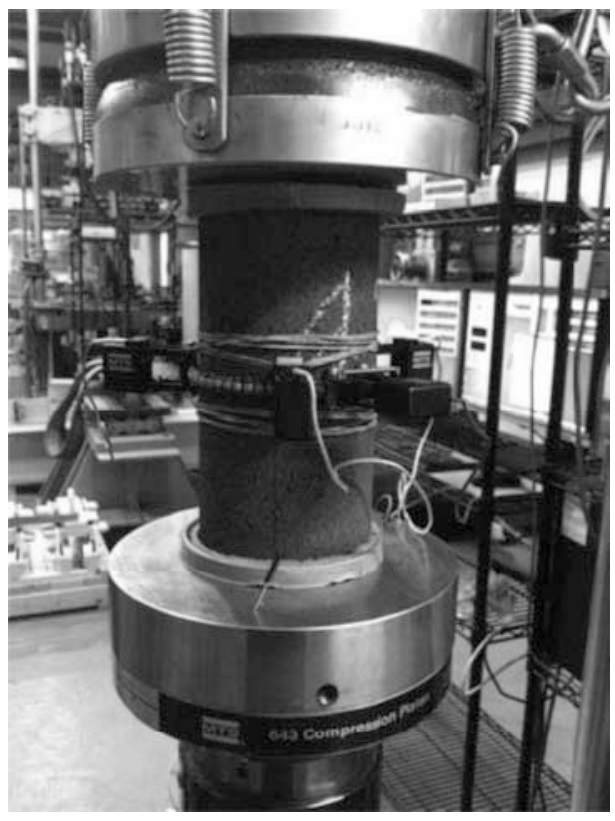

Figure 3. Layout of the sample during compression tests 


\section{Results and discussion}

\section{$\underline{\text { Samples compaction }}$}

In the ASTM D1557-09 standard, the compaction process is done in five layers to achieve a specimen height of nearly $115 \mathrm{~mm} \mathrm{(4.5}$ in), thus approximately $23 \mathrm{~mm}$ height per layer. To reach the same height per layer for a $200 \mathrm{~mm}$ sample, the specimen must be compacted into 8 to 10 layers. The two methods were compared for a similar total number of impacts, between 120 and 130 impacts. Samples consolidated in 10 layers for 150 and 170 impacts were done in order to assess the effect of densification on the mechanical properties with the actual fabrication method (Figures 4 and 5).

The apparent density results for the compaction method with 10 layers are shown in Figure 6 as a function of the total number of impacts. The minimum apparent density reached within this method at 110 impacts was $1.57 \mathrm{~g} / \mathrm{cm}^{3}$ and the maximum at 220 impacts was $1.65 \mathrm{~g} / \mathrm{cm}^{3}$. Although further experiments may have been conducted for superior values, the apparent densities obtained for 210 and 220 impacts show that a maximum density has been fairly reached. More compactive effort could still slightly increase the density, but might result into crushing the aggregates, thus lowering the mechanical properties of the samples according to Faaness et al. [10]. Further analysis would be required to see if crushing occurred for lower number of impacts. Moreover, for compaction exceeding 220 impacts, the pitch contained in the ramming paste is sticking out and adheres to the mold. For a number of impacts below 110, the total height of the green ramming paste becomes too high to perform dynamic compaction in the actual mold and the clearance is too short for a taller mold. Therefore, it would require modifying the actual apparatus.

\section{Mass loss and baked apparent density}

Six different sets of parameters with three specimen replicates for each set (Table I) were done in order to assess the effect of the number of layers and impacts on the apparent density distribution and the mechanical properties of the samples. The mass loss for all samples fluctuates between $10.89 \%$ and $11.21 \%$, which correspond to the emanation of volatiles and carbonization of the pitch. The baked apparent density obtained for samples consolidated into 120 impacts were in the same range for the 8 and 10 layer methods, as seen in Figure 5. Their density distributions were compared with a CT scan.

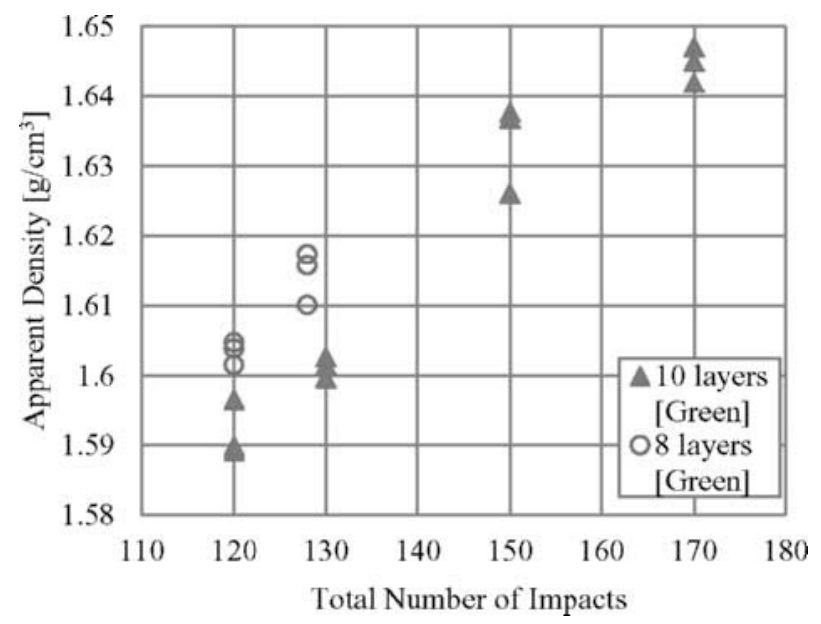

Figure 4. Green apparent density of the scanned samples

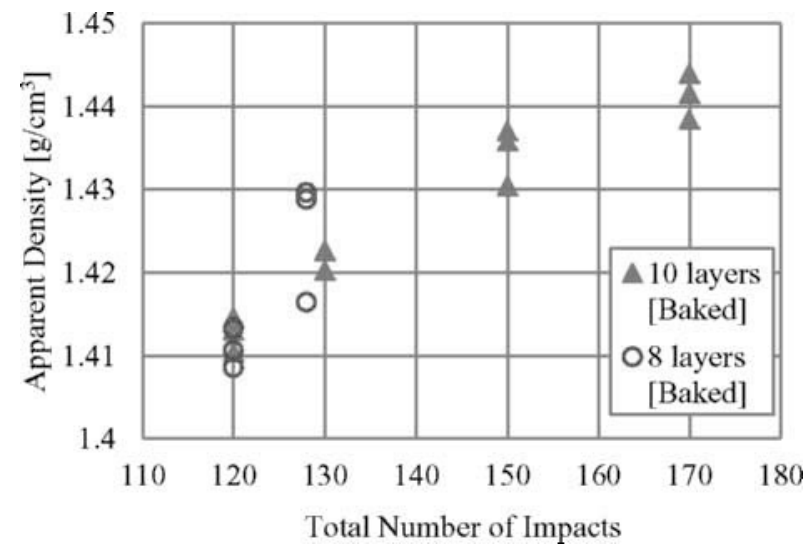

Figure 5. Baked apparent density of the scanned samples

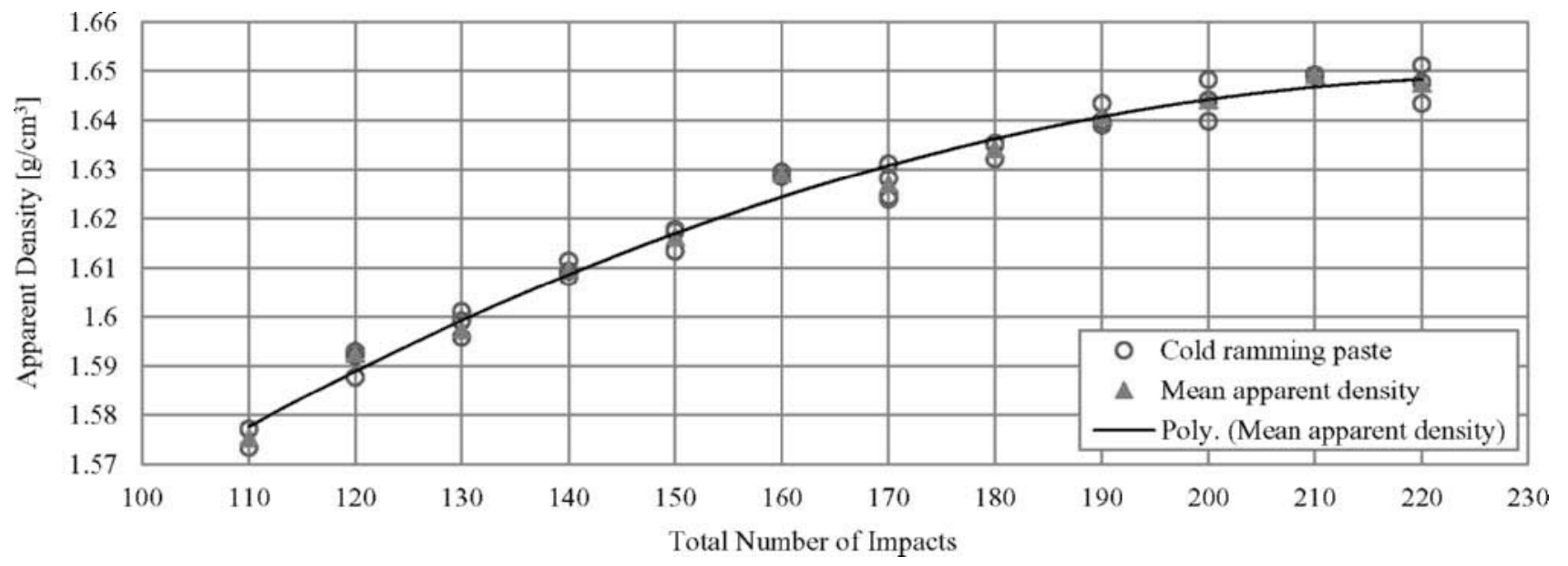

Figure 6. Compaction curve of the 10 layers compaction method 


\section{$\underline{\text { X-Ray computed tomography }}$}

The CT number, in Hounsfield Units (HU), is related to the XRay attenuation coefficient as explained by Picard et al. [5]. It ranges from -1000 for air to 3000 for dense materials. The main hurdle with the estimation of the density, using a linear relation between the CT number and the density, is the calibration using a representative sample. The choice of either one or another sample' baked apparent density must be made in an attempt to reduce the estimation error for the entire set. At first, the overall mean CT number for each specimen was computed. Then, considering the density of air at ambient temperature $\left(0.0011 \mathrm{~g} / \mathrm{cm}^{3}\right)$, and knowing the baked apparent density of the chosen sample (Table 2 ), the linear relation was established:

$\rho=0.0011 \times$ CT number +1.0709

Table 2. Properties of the representative sample

\begin{tabular}{|c|c|c|c|c|}
\hline $\begin{array}{l}\text { Number } \\
\text { of } \\
\text { layers }\end{array}$ & $\begin{array}{l}\text { Number } \\
\text { of } \\
\text { impacts }\end{array}$ & $\begin{array}{l}\text { Mean } \\
\mathrm{CT} \\
\text { number }\end{array}$ & $\begin{array}{l}\text { Green } \\
\text { apparent } \\
\text { density } \\
\left(\mathrm{g} / \mathrm{cm}^{3}\right)\end{array}$ & $\begin{array}{l}\text { Baked } \\
\text { apparent } \\
\text { density } \\
\left(\mathrm{g} / \mathrm{cm}^{3}\right)\end{array}$ \\
\hline 10 & 120 & 308,95 & 1.60 & 1.41 \\
\hline
\end{tabular}

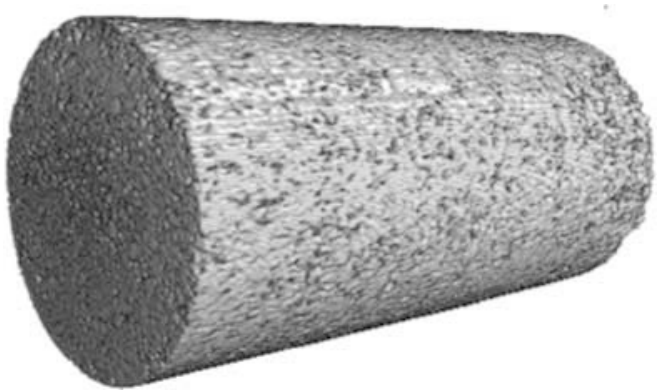

Figure 7. 3D view of a typical CT scan on a sample compacted in 10 layers with 130 impacts

Although the density distribution of a sample might not be visible on its surface with unaided eyes (Figure 7), the CT scan reveals the obvious distinction between the compaction methods, i.e. between 8 layers and 10 layers. Figures 8 and 9 show respectively samples of measured baked densities of $1.41 \mathrm{~g} / \mathrm{cm}^{3}$ each. The 8 layer sample has large fluctuations between its peeks, accentuated with the length of each layer. However, the distribution is far from being uniform for the case of the 10 layer sample, but the difference between the bottom and the top of each wave is less for the same amount of impacts. What is common to both samples is the prompt drop of density on the last layer being compacted. The resulting number of impacts on the other layers being larger than the last one, the top layer of the sample is not as well consolidated. The small variations within the wave itself come from the numeric approximation between two slices whose width is $0.6 \mathrm{~mm}$, which corresponds to the voxel thickness.

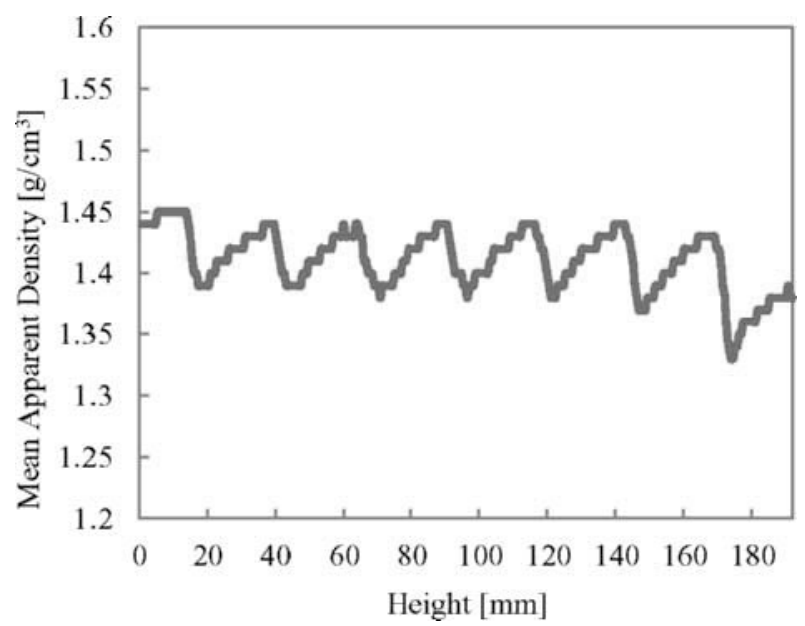

Figure 8 . Density distribution of a baked sample compacted in 8 layers with 120 total impacts

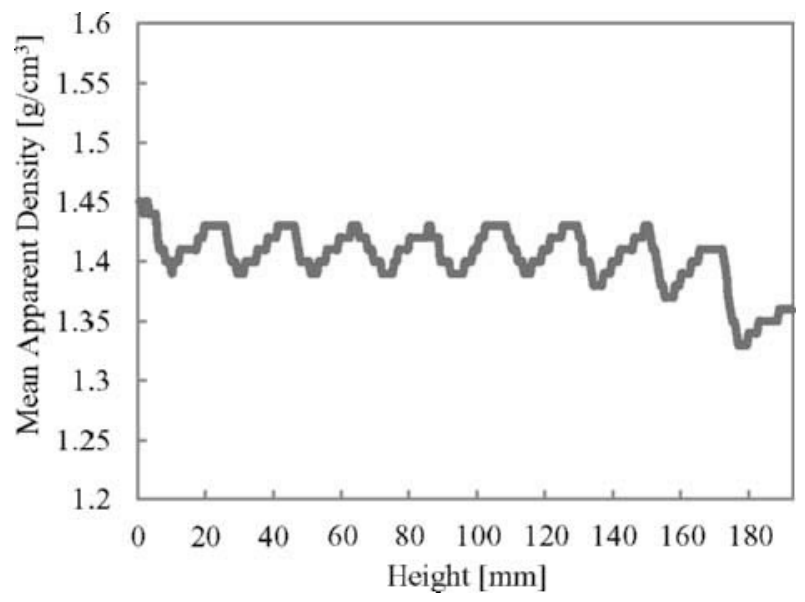

Figure 9. Density distribution of a baked sample compacted in 10 layers with 120 total impacts

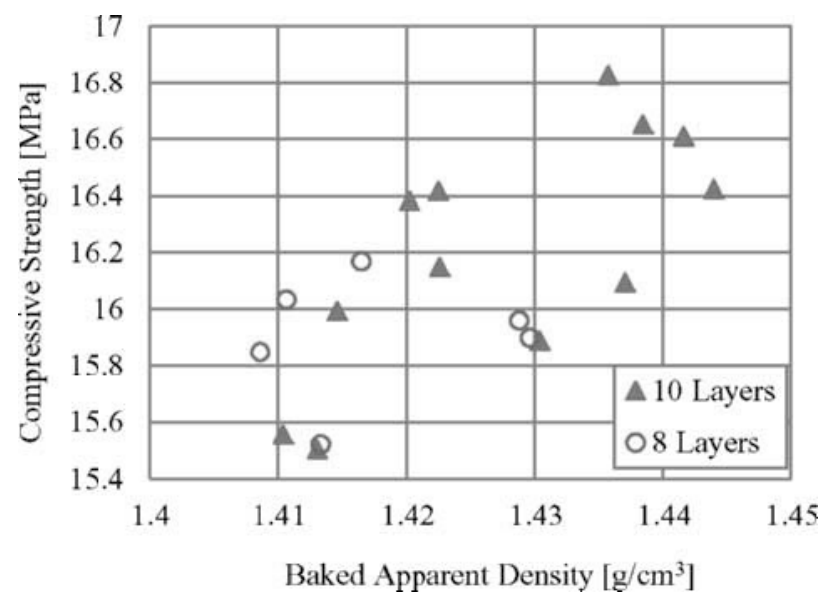

Figure 10. Compressive strength of the baked samples 
The compressive strength (Figure 10) of the baked samples do not represent the expected augmentation of mechanical properties following the raise in densification level and seem to mark the presence of easily crushable particles. As mentioned by Faaness et al. [10], the mechanical strength of the baked samples increases with the augmentation of apparent density for paste containing an insignificant amount of easily crushable material. As particle starts crushing, that linear relationship breaks down at a particular density level and thus the experimental values scatter. For paste with large amount of easily crushable particles, the break-down might occur at low densification level, affecting the mechanical strength. From the results of Figure 10, it can be seen that the compressive strength scatters through the entire set of data though a slight augmentation can be observed with the increase of baked apparent density. Furthermore, the most likely weakest link inside the baked specimen being the carbonized binder, it is plausible that densification has little influence on mechanical properties comparing to the compaction method of cold ramming paste for the same baking temperature. As seen on Figure 10, the compressive strength range is surprisingly thin as most of the samples are rallied between the range of 15.8 and $16.4 \mathrm{MPa}$.

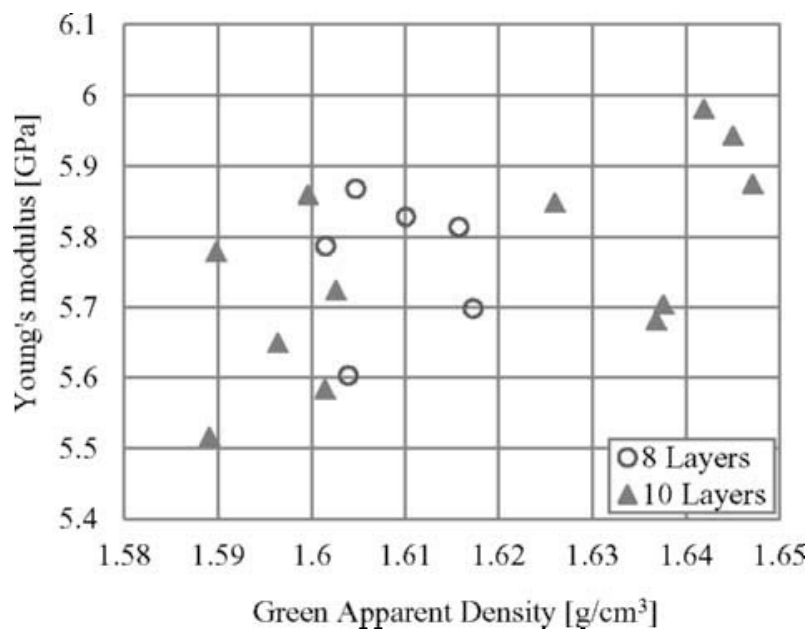

Figure 11. Young's modulus related to green apparent density

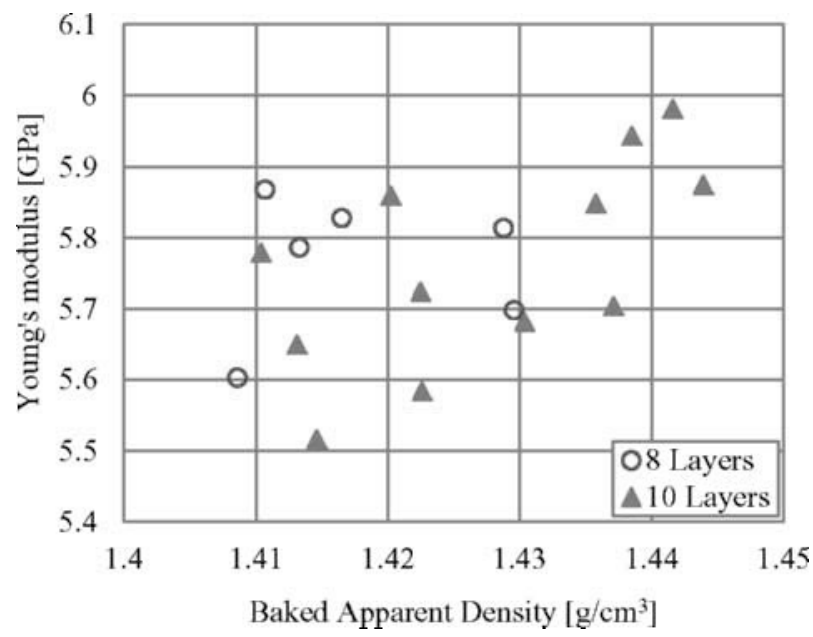

Figure 12. Young's modulus related to baked apparent density

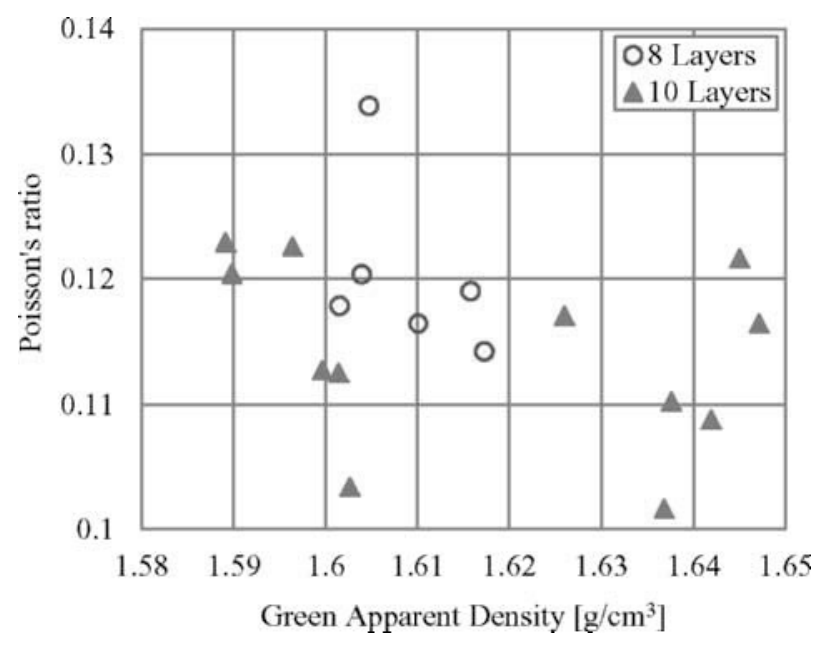

Figure 13. Poisson's ratio related to green apparent density

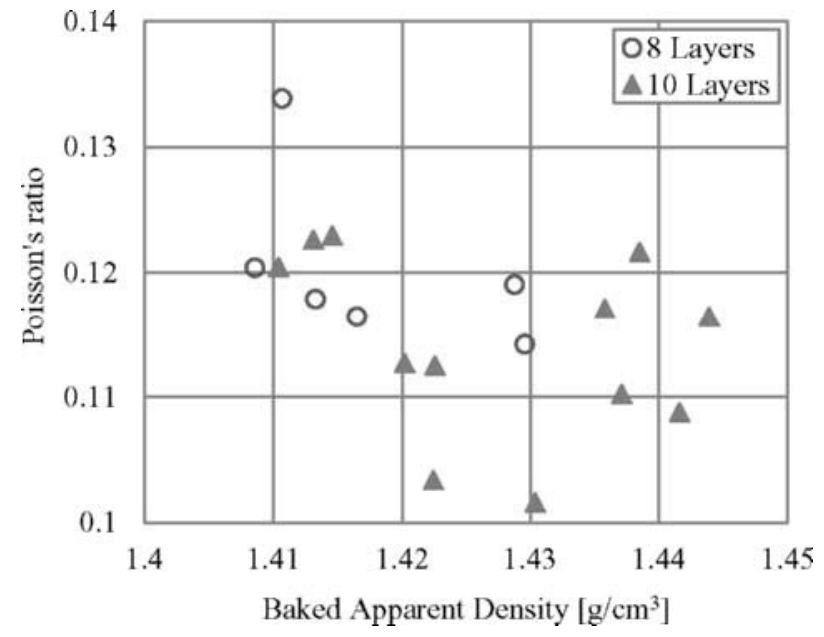

Figure 14. Poisson's ratio related to baked apparent density

The results obtained for Young's modulus and Poisson's ratio, reinforce the idea that the densification of the paste within the aimed green apparent density range, has little influence on the mechanical properties of the baked ramming paste. The compaction into 8 or 10 layers show quite similar results (Figure 11 to 14) for the same baking temperature. The average Young's modulus obtained is $5.76 \mathrm{GPa}$ with a standard deviation of 0.13 GPa. A small augmentation through the data set can be observed over the baked density range. Poisson's ratio is ranged between 0.10 and 0.14 , which correspond to quasi-brittle material. The average value for Poisson's ratio is 0.12 with a standard deviation of 0.01 . 


\section{$\underline{\text { Rupture of the baked samples }}$}

The resulting rupture pattern is illustrated in Figure 11. The rupture starts at the top of the sample, which is considered as the weak zone (Figure 8 and 9), i.e. having the lowest density. The cracks, going through the sample at an angle of approximately $45^{\circ}$, never reached the bottom face of the sample. The same rupture pattern occurred in each and every tested sample.

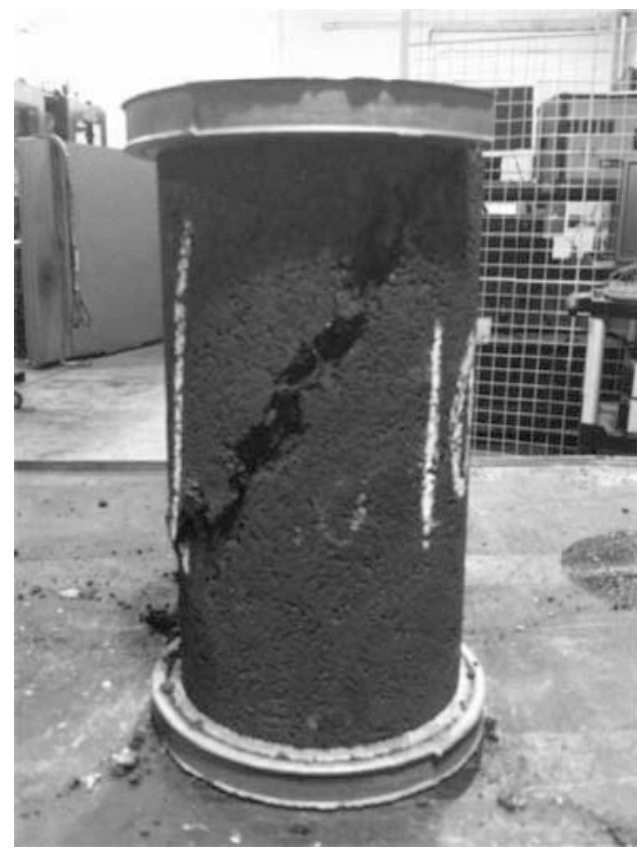

Figure 15. Typical rupture of the baked samples

Conclusion

A new compaction method was developed to obtain larger size sample with significant radial strain amplitude in order to feed three-dimensional creep model. The green paste was rammed in a circular pattern with a mechanical rammer for 10 layers with different totals of number of impacts. The achieved apparent densities were in good accordance with the results of the average density of a representative sample of peripheral joint [4].

Eighteen samples with different parameters were consolidated and baked at $1000^{\circ} \mathrm{C}$ to assess the mechanical properties of the cold ramming paste and density distribution. X-Ray computed tomography was performed on each sample to evaluate the density distribution of the baked specimens. By increasing the number of layers, the recursive fluctuation amplitude for each layer tends to decrease and thus the sample become more uniform. As the last layer is subjected to a prompt drop in apparent density, it would be recommended to remove that layer after baking before proceeding to the mechanical tests.

The Young's modulus, the Poisson's ratio and the compressive strength of the specimens showed that the densification has more or less influence on the mechanical properties of the ramming paste for the specified range of baked apparent density. The rupture pattern being the same for each and every tested sample shows that the samples are fabricated in a repeatable way.

\section{Acknowledgements}

The authors gratefully acknowledge the financial support provided by Alcoa Inc., the Natural Sciences and Engineering Research Council of Canada and the technical support of the Aluminium Research Centre - REGAL.

\section{References}

1. M. Sørlie, and H. Øye, Cathodes in Aluminium Electrolysis, Aluminium-Verlag Marketing \& Kommunikation $\mathrm{GmbH}$, Dusseldrof, Germany, $3^{\text {rd }}$ edition, 2010.

2. F. Hiltmann and K. H. Meulemann, "Ramming Paste Properties and Cell Performance", Light Metals 2000, TMS, 2000, p. 405-411.

3. ISO 17544:2004, "Carbonaceous Materials Used in the Production of Aluminium - Cold and tepid ramming pastes - Determination of rammability of unbaked pastes".

4. S. Orangi, D. Picard, H. Alamdari, D. Ziegler, M. Fafard, "Development of Representative Assembly for Fabrication of Cold Ramming Paste Samples at Laboratory", Paper presented at the $50^{\text {th }}$ COM, Montreal, Quebec, October $3^{\text {rd }} 2011$, Light Metals.

5. D. Picard, H. Alamdari, D. Ziegler, P. St-Arnaud, M. Fafard, "Characterization of a full-scale prebaked carbon anode using X-Ray computerized tomography", Light Metals 2011, TMS, 2011, p. 973-978.

6. ASTM D1557-09, "Laboratory Compaction Characteristics of Soil Using Modified Effort", 2009.

7. ASTM D5502-00, "Apparent Density by Physical Measurements of Manufactured Anode and Cathode Carbon Used by the Aluminum Industry", 2000.

8. ISO 20202:2004, "Carbonaceous Materials Used in the Production of Aluminium - Cold and tepid ramming pastes - Preparation of baked test pieces and determination of loss on baking".

9. ISO 18515:2007, "Carbonaceous Materials for the Production of Aluminium - Cathode blocks and baked anodes - Determination of compressive strength".

10. B. M. Faaness, H. Gran, M. Sørlie, "Ramming Paste Related Failures in Cathode Linings", Light Metals 1989, 1989, p. 633-639. 